\title{
Thermo-mechanical simulations in double-sided heat transfer power assemblies.
}

\author{
E. Woirgard; I. Favre; JY Deletage; S. Azzopardi; \\ R. Leon*; G. Convenant*; \\ Z. Khatir**. \\ Université de Bordeaux I - 351 Cours de la Libération - 33405 TALENCE - France \\ *Valeo-CEE - 5 avenue Newton - 78180 MONTIGNY LE BRETONNEUX - France \\ ** Inrets - 25 allée des Marronniers - Satory - 78000 Versailles - France
}

\begin{abstract}
In power assemblies, heat transfer due to the die selfheating is one of the most important point on time life assemblies. Heat has to be evacuated toward the baseplate not to weaken the solder joint under the die. Double-sided assemblies are attractive for heat transfer and many studies were initiated to have better heat transfer. So, we can observe less density energy deformation (DED) in solder joints and more stresses in the die. The purpose of this paper is to quantify the part of DED in the joint compared to the stresses in the die and finally to see the best configuration between single or double face assemblies.
\end{abstract}

\section{Introduction}

In conventional power assemblies, the silicon die is mounted on a substrate (leadframe, Direct Bonded Copper or DBC, ...). In a Single Face Assembly (SFA) heat transfer configuration, the heat is mainly driven toward the base-plate through the solder joint. In a Double Face Assembly (DFA), the die is mounted between two substrates which allow less mechanical stress in the solder joints (upper and lower) as well as a better heat dissipation due to the double-side configuration.

In this work, we propose to compare and to quantify the density energy deformation in the solder joints in both cases (simple and double faces power assemblies) by using finite elements simulations. The goal is also to show when appear the stresses induced in the silicon die used in these assemblies.

\section{Models description}

Four cases were investigated for comparison: two single faces as reference and two double face power assemblies. We have considered power assemblies made with a die soldered with a lead-free alloy (SAC $305)$ in simple and double face substrates. The fusion temperature of the joint is $217^{\circ} \mathrm{C}$.
The two SFA are composed of dice soldered on leadframe (figure 1) and DBC (figure 2) substrates.

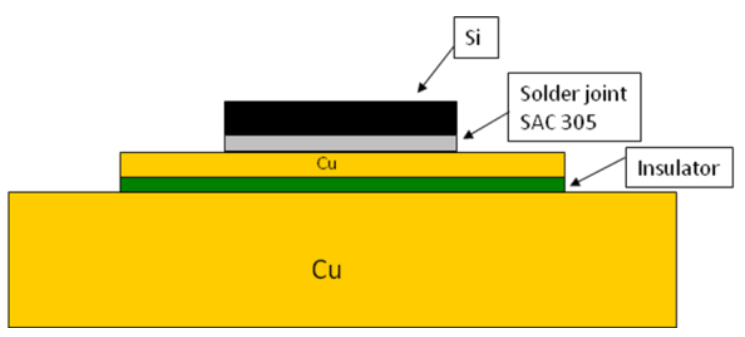

Figure 1 - Leadframe model

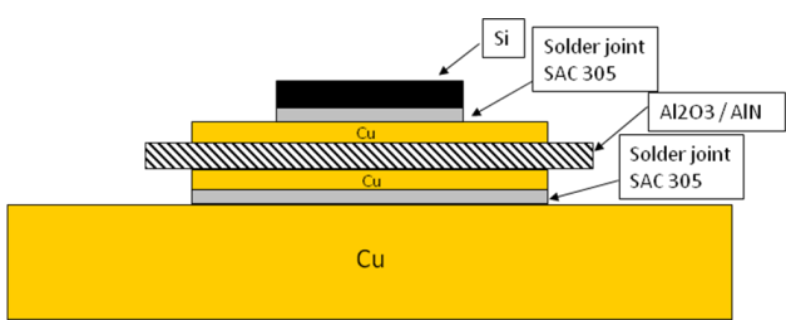

Figure 2 - DBC model

Regarding the DFA, one DFA (figure 3) is made by including a double-side soldered die between two full joints top and bottom between two copper-basedsubstrates (DFFJ : double face full joints).

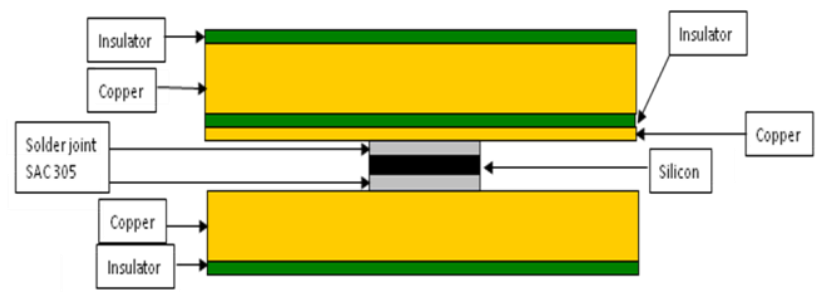

$\underline{\text { Figure } 3}$ - DFFJ model 
The second DFA (figure 4) is composed by a die soldered with a bottom full joint and top balls joint between two copper-based-substrates (DFBJ : double face ball joints).

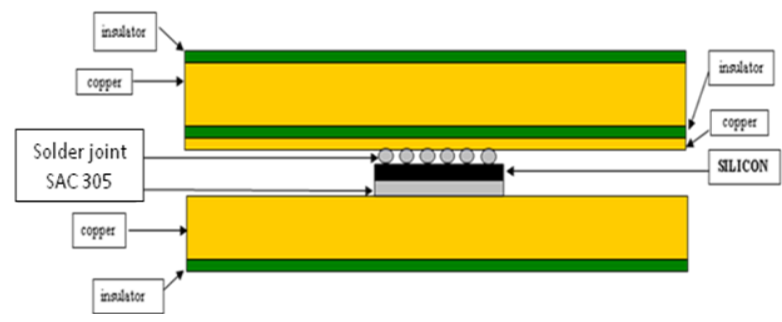

Figure 4 - DFBJ model

\section{$\underline{\text { Geometrical characteristics : }}$}

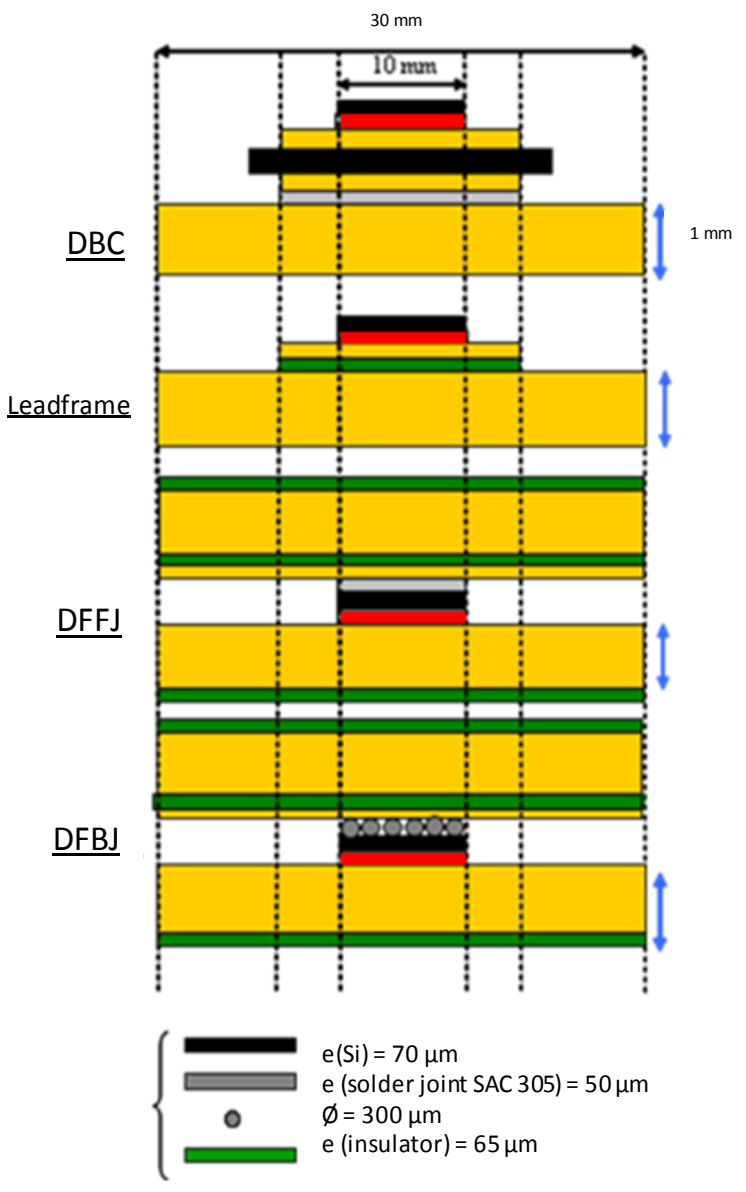

Figure 5-Geometrical characteristics of assemblies
Material characteristics :

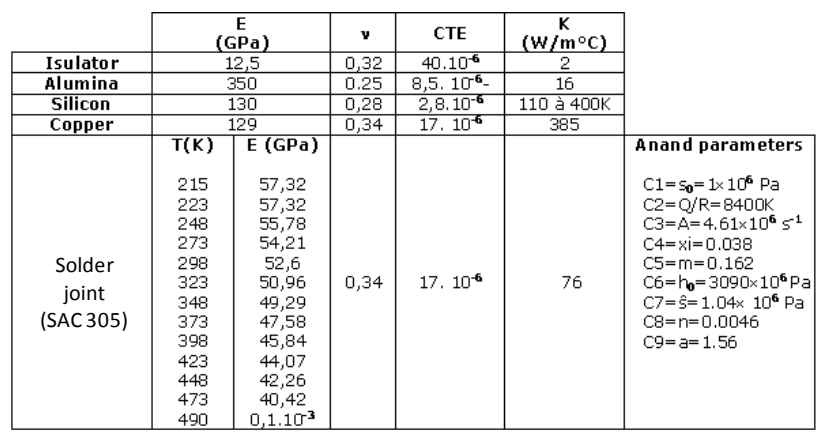

$\underline{\text { Table } 1}$ - Material characteristics of assemblies

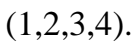

Density energy deformation in solder joints and stresses in silicon chip were analyzed for these four cases in order to highlight which configuration is more reliable in term of life time assembly.

\section{Methodology}

Each configuration has been modelized with a 3Dfinite element. Same thermal shocks and power cycling were applied to the four models and their thermal and thermo-mechanical behaviors were analyzed.

Thermal shocks :

Considered thermal shocks are severe. The thermal amplitude is $-55^{\circ} \mathrm{C}$ to $+125^{\circ} \mathrm{C}$. We applied the following sequence to the assemblies:

1) down temperature after refusion from $217^{\circ} \mathrm{C}$ (fusion temperature of soldered joint) to $20^{\circ} \mathrm{C}$ (ambient) in 3 minutes.

2) 3 months storage at $20^{\circ} \mathrm{C}$.

3) 5 thermal shocks from $-55^{\circ} \mathrm{C}$ to $+125^{\circ} \mathrm{C}$.

During thermal shocks, time plateau are 15 minutes (900 seconds), up and down temperature time are $50^{\circ} \mathrm{C} /$ minute.

The following figure (figure 6) shows the sequence applied for thermal shocks.

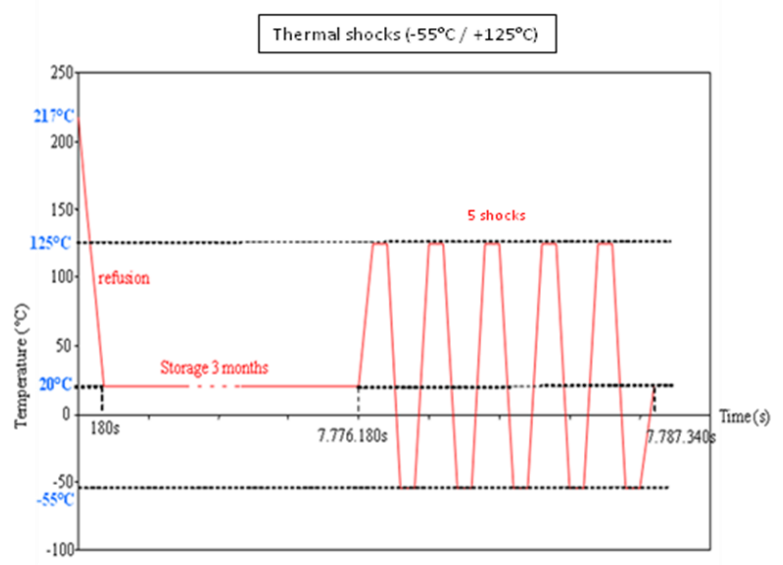

$\underline{\text { Figure } 6}$ - Thermal shocks 


\section{Power cycling:}

Power cycling corresponds to mission profiles. Like thermal shocks, we applied the same 2 first steps and then 2 power cycling of one hour each. So, the sequence applied is the following one :

1) down temperature after refusion from $217^{\circ} \mathrm{C}$ (fusion temperature of soldered joint) to ambient $\left(20^{\circ} \mathrm{C}\right)$ in 3 minutes.

2) 3 months storage at $20^{\circ} \mathrm{C}$.

3) 2 power cycling of one hour each.

The following figure (figure 7) shows the third step : power cycling.

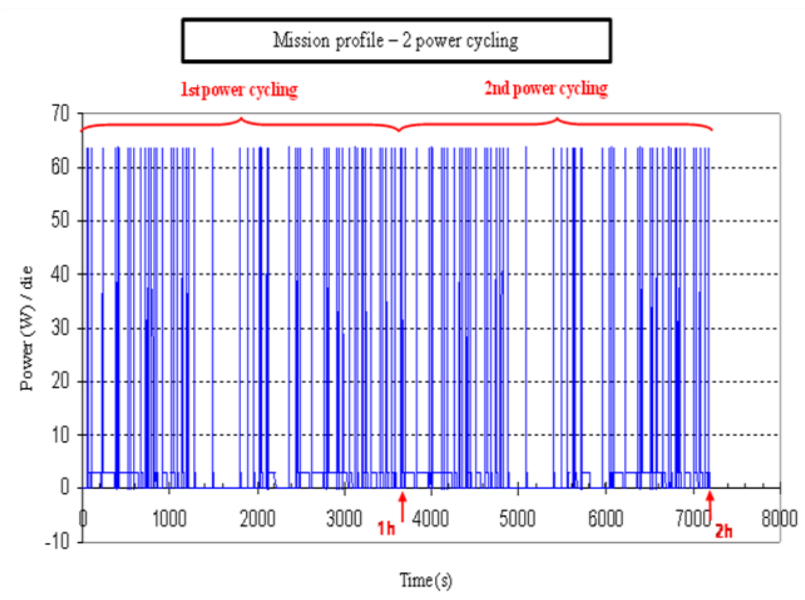

$\underline{\text { Figure } 7}$ - Power cycling

\section{FEM simulations and results}

The simulations made by finite element modelling (FEM) is based on thermal and thermo-mechanical approaches which are taken into account to calculate the density energy deformation dissipated in the solder joint located under the die simultaneously with the stresses induced in the silicon chip.

\section{Limit conditions :}

- Temperature reference is $490^{\circ} \mathrm{K}$.

- Due to symmetry, we meshed only $1 / 4$ of structure.

- Z translation of the node under the die center is blocked.

For power cycling :

- The power dissipated in all the die is $40 \mathrm{~W}$ for thermal simulations.

- The ambient temperature is $373^{\circ} \mathrm{K}$.

- The exchange coefficient (h) vary from 500 to $10000 \mathrm{~W} / \mathrm{m}^{2} .{ }^{\circ} \mathrm{K}$ ( under the base-plate : down for SFA, up and down for DFA)

\section{Simualtions and results :}

For each configuration, we applied thermal shocks (passive cycles) and power cycling (active cycles).

For thermal shocks, we looked after two results:

- The maximal stresses in the die at the end of the five thermal shocks.

- The density energy deformation (DED) to the area (limited to 10 nodes) the most stressed in the solder joint under the die (see "red joint" in figure 5). We regard this joint in order to compare SFA and DFA.

For power cycling, we looked after:

- The maximal stresses in the die at the end of the refusion.

- The density energy deformation (DED) to the area the most stressed in the solder joint under the die for an exchange coefficient of $1000 \mathrm{~W} / \mathrm{m}^{2} .^{\circ} \mathrm{K}$.

We resumed and classified the results in the following table 2 .

\begin{tabular}{|c|c|c|c|c|}
\hline & Leadframe & $D B C$ & DFFJ & DF BJ \\
\hline \multicolumn{5}{|c|}{ Thermal shocks } \\
\hline $\begin{array}{l}\text { Maximal stresses in silicium } \\
\text { (end of } 5 \text { chocks) }\end{array}$ & $\begin{array}{l}\text { level } 2 \\
\text { (401 MPa) }\end{array}$ & $\begin{array}{l}\text { level } 1 \\
(233 \mathrm{MPa})\end{array}$ & $\begin{array}{l}\text { level } 4 \\
(585 \mathrm{MPa})\end{array}$ & $\begin{array}{l}\text { level } 3 \\
(476 \mathrm{MPa})\end{array}$ \\
\hline $\begin{array}{l}\text { DED } \\
\text { (to the area the most stressed } \\
\text { in the solder join under the die) }\end{array}$ & $\begin{array}{l}\text { level } 4 \\
(8,5 \mathrm{~J} / \mathrm{cm} 3)\end{array}$ & $\begin{array}{l}\text { level } 3 \\
(4,6 \mathrm{~J} / \mathrm{cm} 3)\end{array}$ & $\begin{array}{l}\text { level } 1 \\
(0,2 \mathrm{~J} / \mathrm{m} 3)\end{array}$ & $\begin{array}{l}\text { level } 2 \\
(0,61 \mathrm{~J} / \mathrm{cm} 3)\end{array}$ \\
\hline \multicolumn{5}{|c|}{ Power cycling } \\
\hline $\begin{array}{l}\text { Maximal stresses in silicium } \\
\text { (end of refusion) }\end{array}$ & $\begin{array}{l}\text { level } 1 \\
(80 \mathrm{MPa})\end{array}$ & $\begin{array}{l}\text { level } 2 \\
(171 \mathrm{MPa})\end{array}$ & $\begin{array}{l}\text { level } 3 \\
\text { (511 } \mathrm{MPa})\end{array}$ & - \\
\hline $\begin{array}{l}\text { DED } \\
\text { (to the area the most stressed } \\
\text { in the solder join under the die) } \\
\left.\text { ( } h=1000 \mathrm{~W} / \mathrm{m}^{2}{ }^{\circ} \cdot \mathrm{K}\right)\end{array}$ & $\begin{array}{l}\text { level } 3 \\
(4,1 \mathrm{~J} / \mathrm{m} 3)\end{array}$ & $\begin{array}{l}\text { level } 2 \\
(2,8 \mathrm{~J} / \mathrm{m} 3)\end{array}$ & $\begin{array}{r}\text { level } 1 \\
(0,3 \mathrm{~J} / \mathrm{cm} 3)\end{array}$ & - \\
\hline
\end{tabular}

Level 1 = smallest value

Level 4 = highest value

Table 2 - Classification of the four configurations considering stresses in the die and DED in the joint under the die.

Regarding that table, we can say:

- the maximal stresses in silicon appear at the end of thermal shocks while in power cycling maximal stresses are due to the assembly fabrication itself because maximal value is at the end of fusion (soldering of the die on substrate).

- in DFA, the die is soldered both sides so more stressed. For power cycling, the maximal stresses in the die are 2.5 time higher for DFA than for DBC model, for example.

- the density energy deformation to the node the most stressed in the solder joint under the die is an indicator of starting crack. The weaker the DED in solder joint will be and the less the assembly will tire.

- for thermal shocks as for power cycling, it is the DFA which has the weaker DED but it is in the DFA that the stresses in the die are greater. 
The more reliable assembly stay the DFA whose global temperature is twice less higher than for SFA because of double side thermal evacuation.

\section{Conclusions}

The results show that the density energy deformation in solder joints under the die, during power cycling or thermal shocks, is lower in DFA configuration. Correlated to this fact, the stresses in the silicon dice are increasing. There are 2.5 times higher compared to a SFA DBC substrate for exemple.

The next step of this work is to study the effects of mechanical stresses in the die on the evolution of electric parameters of silicon.

\section{Acknowledgments}

This work is part of EPO-Auto+ French programme from PREDIT "Programme of research, experimentation and innovation in land transport".

PREDIT is a programme started and implemented by the french ministries in charge of research, transport, environment and industry, the ADEME and the ANVAR.

\section{References}

1. Wang, Cheng, Becker and Wilde, "Applying Anand model to represent the viscoplastic deformation behaviour of solder alloys", Journal of electronic packaging, vol.123, p.249, September 2001.

2. Pecht and all, "Electronic Packaging, Materials and their properties", CRC Press, 1999.

3. Amagai M., Watanabe M., Omiya M., Kishimoto K., Shibuyza T., "Mechanical characterisation of SnAg-based lead-free solders", Microelectronics Reliability, 2002, Volume 42, p 951-966

4. NIST, data base, http://www.metallurgy.nist.gov/solder 